\title{
Keeping Track: Triangulating Methods to Measure the Food Environment: A Pilot Study
}

\author{
Windi Lameck Marwa ${ }^{1 *}$, Samantha Davis², Claire Griffiths ${ }^{3}$, Duncan Radley ${ }^{4}$ and Emma Strachan ${ }^{5}$ \\ ${ }^{1}$ Carnegie School of Sport, Leeds Beckett University, Leeds UK \\ ${ }^{2}$ School of Health and Community Studies, Leeds Beckett University, Leeds UK \\ ${ }^{3}$ Reader, Carnegie School of Sport, Leeds Beckett University, Leeds UK \\ ${ }^{4}$ Senior Research Fellow, Carnegie School of Sport, Leeds Beckett University, Leeds UK \\ ${ }^{5}$ Health Improvement Specialist (Food and Nutrition), Adults and Health Directorate Leeds City Council, Leeds UK
}

Submission: January 25, 2019; Published: February 06, 2019

*Corresponding author: Windi Lameck Marwa, Carnegie School of Sport, Leeds Beckett University, UK

\begin{abstract}
This article explores the potential of using Global Positioning Systems (GPS) to capture valuable data in measuring food environments. Such data, when triangulated with more conventional methods of collection, for example daily 24-hour dietary recalls and food purchase receipts, allow researchers to gain a fuller picture of individual activity in dynamic food environments. This is vital to understanding both individual and environmental factors that influence individuals' decision and behaviour patterns within food environments. However, the practicalities of triangulating data collection methods are challenging to both researchers and participants, and so a pilot study was undertaken to test different methods of measuring the food environment. Recruitment for the pilot study took place between August and September 2017 and of the 16 participants initially recruited, 13 took part and completed all data collection methods and provided valuable feedback about the experience. The participants' perspectives on the process of triangulating methods, along with the findings, are discussed in the paper.
\end{abstract}

Keywords: Global Positioning Systems; Food environment; Activity-space; Obesity; Dietary recalls

Abbreviation: GPS: Global Positioning Systems; BMI: Body Mass Index; CSV: Comma Separated Values; SES: Socioeconomic Status; ICT: Information and Communication Technology; MMM: My Meal Mate; MFP: My Fitness Pal

\section{Introduction}

Obesity poses a global health challenge Butland et al. [1] and in England recent data suggests there has been a threefold increase in obesity prevalence in the last three decades with estimations suggesting that by 2050 more than $50 \%$ of the British population could be obese. Obesity, put very simply, occurs when there is a positive energy imbalance, however, the factors that contribute to such an imbalance are complex and multi-factorial [2]. According to Chaix et al. [3] the environmental determinants of obesity are particularly significant and wideranging such as the food production industry; food marketing; the urban sprawl; a growth in the number of restaurants; the rise of private over public modes of transport and the general sedentary nature of $21^{\text {st }}$ century life-both at work and home. These factors, in addition to the unequal geographic distribution of resources that influence obesity (leisure facilities, fast food outlets etc.) have created a favourable context for the obesity epidemic [3]. Thus, any future interventions aimed at addressing this epidemic effectively need to better understand individual behaviours within food environments; that is to say, all those places that offer opportunities to access and consume food [4].
This focus on food environments offers a more realistic unit of measurement than for example, the residential neighbourhood the most common unit of measurement used in neighbourhood and health studies and is justified because, according to Chaix et al. [3], people spend only a fraction of their time in residential neighbourhoods. It is clear then that, in terms of addressing the rising trend in obesity, the study of food environments could make a significant contribution to knowledge. Indeed, this has already begun to draw the attention of policymakers, but the evidence base is still weak and inconsistent [5-7]. For example, a review by Caspi et al. [8] found that some studies reported positive associations between food accessibility and dietary outcomes while others reported a negative or null association. This inconsistency could be explained by contextual factors, or by the different classifications used for food outlets, or by the variability of methods used in previous studies [9]. Another reason could be what is referred to as the 'local trap' or 'residential trap', a phenomenon where researchers return to the local residential neighbourhood as the sole unit of measurement to gather data about food environments. A number of scholars are critical of this approach and expresses a concern about the 


\section{Juniper Online Journal of Public Health}

rising trend of this practice [10-16]. In a systematic review undertaken by Chaix et al. [3] over $90 \%$ of the studies examined were exclusively focused on the residential neighbourhood. Cummins [10] suggests a way out of this 'trap' could be to view food environments not as places where people live, but as Townshend \& Lake [4] suggest: all those places and settings that offer exposure to food including the routes between those places. For the purpose of this paper, these activity places shall be referred to as activity-based food environments [17].

A study undertaken in Detroit in 2011 (US) revealed that activity spaces were much larger than residential neighbourhoods and that there was a significant statistical relationship between dietary behaviours and activity space environmental characteristics [18]. Similar conclusions were also derived from a study carried out by Kestens et al. [19] in Montreal and Quebec City, Canada. Informed by travel survey data and food outlets, this study found that using activity space as a unit of measurement rather than the traditional residentialbased unit provided deep and meaningful insights as to how the environment influences weight status and health outcomes. This is largely due to the fact that the activity space approach enables the researcher to capture regular and daily exposures in multiple settings, offering a richer research perspective compared to the limited and reductionist analysis that has tended to result from focussing on residential neighbourhoods.

This wider focus on activity spaces has been facilitated by the development of Geographic Positioning Systems (GPS) which can be used to track the movements of people throughout the day for several days. These advancements in geospatial technology have eased the technological challenges of measuring food environments, and recent studies have begun to rely on GPS technologies to not only assess dietary behaviour of individuals but their exposure to other influential factors which shape their daily environments such as opportunities for physical activity [18]. Yet despite the increased use of GPS technology in health research, its application in researching food environments using the broader concept of an activity space is generally still scarce [20].

The research being undertaken currently seeks to address this gap by adopting the activity-based food environment as a unit of measurement and deploying multiple methods to capture individual behaviours within those spaces. The findings that are reported here are from a pilot study that informs the fullscale study scheduled to take place in 2018/19. Triangulating methods can be challenging Casey \& Murphy [21], particularly if the method/s are new and have never been trialled together before. According to our knowledge, there has been no study of a food environment (one which goes beyond the measurement unit of the residential neighbourhood) that triangulates a number of different data collection methods purposefully designed to elicit and integrate the multiple perspectives of participants, gatekeepers and researchers. This pilot study therefore seeks to explore these challenges and thus focuses on issues of feasibility and validity when pursuing complex research designs of this kind.

\section{Materials and Methods}

The pilot study was conducted between mid-August and mid-September 2017 and sixteen participants were initially recruited. The study only included participants who were Leeds City Council employees residing in Leeds aged 18 years old and above, literate, digitally literate, with access to the internet and available to take part in the study. The study received ethical approval from Leeds Beckett University Research Ethics Committee and permission to conduct research by the Leeds City Council Research Governance Board.

Participants were given a questionnaire via Qualtrics which asked them about their socio-demographic characteristics, socio-economic status and their residential postcodes as well as personal information about their height and weight. Participants were then issued with GPS tracking devices and asked to wear them for a period of seven days. The GPS devices used in this pilot study were Garmin Foretrex 301 and 401 which were set to record GPS points every 30 seconds whenever they moved outside their residential areas. Data for this pilot study was not only collected in this way but from using two other methods also: Myfood24-which is an automated, online self-administered tool that captures dietary data (24hour recalls) and by asking participants to collect the receipts of all food purchases made during that week. At the end of the data collection period the participants were invited to give feedback about their experiences using these three methods.

\section{Data Analysis}

GPS data were downloaded from the GPS devices in GPS exchange (GPX) format then converted to Comma Separated Values (CSV) format, cleaned and stored on a password-protected computer. The data from the receipts were extracted manually and inputted into an excels spreadsheet. This spreadsheet also included personal information about the participants' height and weight, Body Mass Index (BMI) and weight status. This data, along with the data downloaded from Qualtrics and Myfood24 was initially cleaned and stored and at a later date collated to form one, single data set. The postcodes of participants' residential areas and food outlets were geo-coded using a Google sheet and Awesome tables to provide the necessary latitudes and longitudes in order to project the information onto maps which was completed using GIS software. Descriptive statistics were performed using $\mathrm{R}$ and spatial analyses were performed using the Geographic Information System (ArcGIS version 10.3.1).

The information extracted from the GPS devices revealed the movements of participants as they engaged in routine daily activities. Noteworthy, the geocoded residential postcode used in the published map was geomasked using a donut geomasking method. The type of information extracted from the receipts highlighted the names and locations of the food outlets the 


\section{Juniper Online Journal of Public Health}

participants visited, the dates and times of the purchases they made, the types of items they purchased and the cost of those items. Myfood24 captured a wide range of dietary information, but for the purpose of this study the dietary information of interest focused on energy intake.

\section{Results}

Out of the 16 participants initially recruited for the study, 1 did not complete the data collection process and 2 withdrew from the study leaving a total of 13 active participants. All

Table 1: Participants Characteristics.

\begin{tabular}{|c|c|c|}
\hline & Characteristics & n (\%) \\
\hline \multirow{5}{*}{ Age (years) } & $25-30$ & $2(15)$ \\
\hline & $31-40$ & $6(46)$ \\
\hline & $41-50$ & $4(31)$ \\
\hline & $50+$ & $1(8)$ \\
\hline & \multicolumn{2}{|c|}{ Min. age $=25$, Max. age $=57$, Mean age $38, S D=8.57$} \\
\hline \multirow{2}{*}{ Employment status } & Part-time & $11(85)$ \\
\hline & Full-time & $2(15)$ \\
\hline \multirow{5}{*}{ Mode of transport } & Car & $8(61)$ \\
\hline & Bus & $2(15)$ \\
\hline & Train & $1(8)$ \\
\hline & Walking & $1(8)$ \\
\hline & Bicycle & $1(8)$ \\
\hline \multirow{4}{*}{ Ethnicity } & White & $7(54)$ \\
\hline & Other white background & $3(23)$ \\
\hline & Indian & $2(15)$ \\
\hline & Pakistani & $1(8)$ \\
\hline \multirow{2}{*}{ Education attainment } & Degree & $5(38)$ \\
\hline & Postgraduate & $8(62)$ \\
\hline \multirow{4}{*}{ Weight status (BMI Kg/m²) } & Underweight $(<\mathrm{s} 18.5)$ & $1(8)$ \\
\hline & Normal weight (18.5 - 24.9) & $9(69)$ \\
\hline & Overweight (25.0 - 29.9) & $0(0)$ \\
\hline & Obese $(\geq 30)$ & $3(23)$ \\
\hline \multirow{5}{*}{ IMD quantile } & 1 (Least deprived & $2(15)$ \\
\hline & 2 & $1(8)$ \\
\hline & 3 & $3(23)$ \\
\hline & 4 & $4(31)$ \\
\hline & 5 (Most deprived) & $3(23)$ \\
\hline \multicolumn{3}{|c|}{ Working hours (Hours) Min. $=7.4$, Max. $=8$, Mean $=7.8, \mathrm{SD}=0.3$} \\
\hline \multicolumn{3}{|c|}{ Total Energy Intake (Kcal/day) Min. = 654.4, Max = 3559.2, Mean = 1827.1} \\
\hline
\end{tabular}

Participant perspectives on using multiple methods of data collection

By and large, most participants found the study to be a useful opportunity to reflect on the dietary aspect of their lives. They were happy to receive instant dietary feedback as noted by one participant: 'I liked instant feedback on a summary of food intake, it then helps me to make quick decisions on the next day i.e. I ate participants were females, and half of them were White [Table1]. Nearly a quarter of participants were obese $\left(\mathrm{BMI} \geq 30 \mathrm{~kg} / \mathrm{m}^{2}\right)$, and more than half of them used a car as their mode of transport to work. All participants were educated to degree level, and most participants were full-time employees of Leeds City Council. On average, the daily total energy intake per participant each day was 1827.10Kcalories [Table1]. Most of the food purchases made were made outside of participants' residential neighbourhoodsthat is to say most purchases were made in or near the workplace and/or end route between the workplace and home [Figure 1]. 


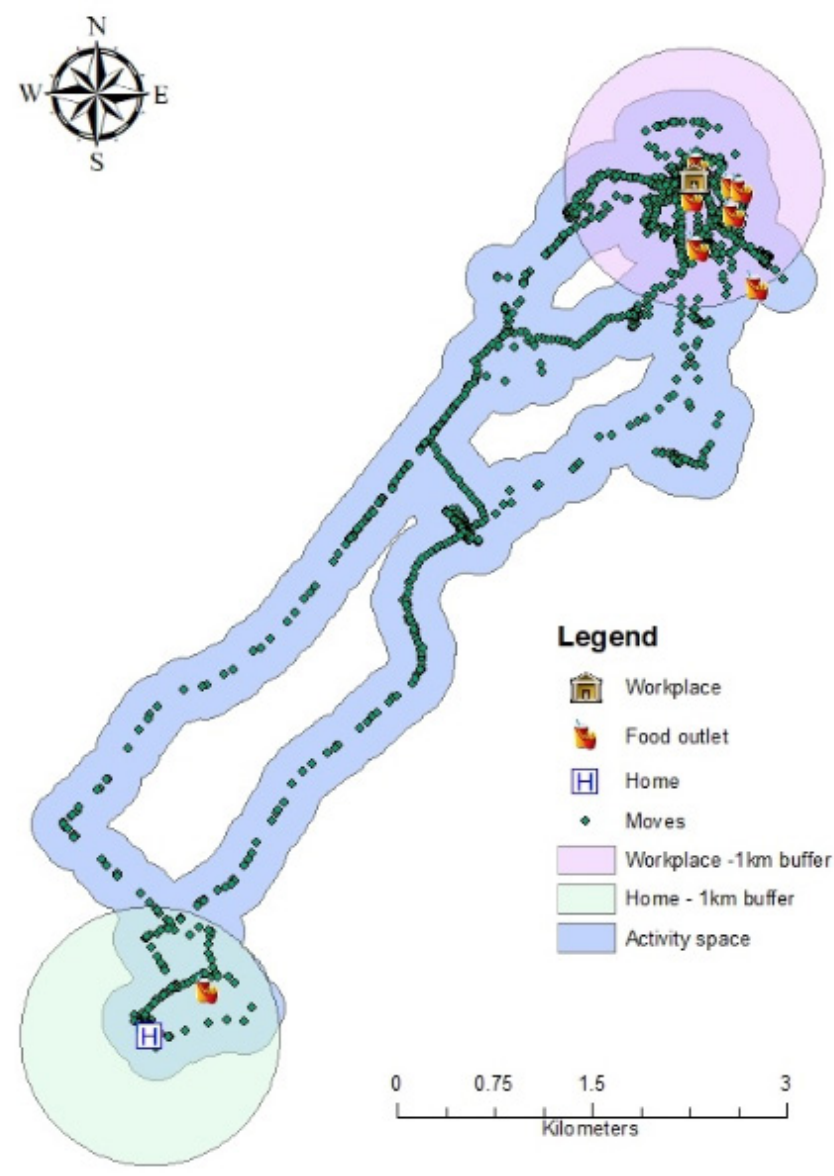

Figure 1: An activity-based food environment example.

\section{Questionnaire and receipt collection}

All the participants reported the experience of completing the questionnaire to be easy, saying it took less time to complete than expected. Receipt collection was reported to be 'fine' by most participants, however two key issues emerged:

a. some food outlets failed to provide a receipt

b. occasionally participants forgot to collect the receipt after purchasing food. To overcome these issues some participants made a note of the food items purchased and the name of the food outlet whenever receipts were not issued, or they forgot to collect receipts.

\section{GPS}

Most of the participants said they were comfortable using GPS although some were concerned with the size of the device and suggested smaller and more user-friendly GPS devices would be better. A few participants reported issues with the number of times they had to change the batteries and suggested using GPS batteries that could retain the charge for a longer time (like a week) as this would minimise the hassle of replacing batteries every day. Some reported problems in remembering to wear the device!

\section{4hour dietary recall (Myfood24)}

Using Myfood24 was a new experience for most participants and so, understandably, they needed a little time to become familiar with it. Myfood24 contains a wide range of food options and whilst this was viewed positively it did sometimes pose a challenge for the participants when they tried to find specific foods. Some participants found the way around this was to use the 'my recipes' tab which enabled them to store and retrieve food items they used frequently. Finding home-made food on the list of food in Myfood24 was reported by some to be challenging. Indeed, one participant, for example, felt that the tool is more inclined towards processed food as reflected in her feedback: '[Myfood24 is] a bit slanted towards ready-made meals...'. Photographs indicating portion sizes were highlighted by some participants as useful in helping them identify their actual food intake.

\section{Reflection on the feasibility and validity of method- ological triangulation}

This pilot study was undertaken to test the feasibility and validity of methodological triangulation which used five different methods to gather data about individual food environments and the food journeys made within these environments. Before 
dealing with the issue of validity we shall first reflect on the feasibility of triangulating the different methods used.

\section{The feasibility of methodological triangulation}

Participants recruited for the pilot study trialled 5 different methods for one week which included using a GPS tracking device, collecting receipts for all food purchases, completing 24hour dietary recalls using Myfood24 (an online 24-hour dietary assessment tool), and a questionnaire containing important sociodemographic and socioeconomic information. Participation in this study demanded a relatively high level of commitment as using five different methods with varying degrees of complexity, simultaneously, for one whole week could potentially be burdensome for participants. For example, whilst food diaries and questionnaires might be quite familiar tools (and therefore pose less difficulty to participants) new and innovative methods such as the GPS tracking device or Myfood24 might potentially be more problematic to understand and use. From a research point of view, difficulties arising with the data collection tools needed to be identified and addressed quickly so as not to affect both the process and outcome of the research. To mitigate against the triangulation of familiar and unfamiliar methods being burdensome to the cohort, the researcher invested considerable time prior to the pilot study to become acquainted with all the data collection tools, troubleshooting potential glitches in their use and identifying practical solutions to overcome such difficulties. Thus, it was necessary for the researcher to introduce, demonstrate and monitor all five methods of data collection and to be on hand throughout the week that data was being collected to problem solve. This was done using a variety of channels for example via email and telephone. Participants were also provided with an information sheet (paper and electronic copies) detailing each of the methods being used in this pilot study.

Upon reflection, embedding some form of training early on for participants proved to be crucial as difficulties were indeed encountered which, had they not been swiftly resolved, might have affected participant engagement and resulted in incomplete and/or inaccurate data. Another crucial factor in the design of the pilot phase was the size of the sample and the decision to keep it small (13) and therefore manageable. This small sample is justifiable because the purpose of the pilot was to identify the feasibility of the approach and to identify any glitches with the methods (individually) or in triangulation so that solutions could be found before scaling up the research later. In addition to the daily support given by the researcher, an incentive was also offered and those who completed the data collection process successfully were entered into a prize draw for a $£ 100$ Amazon voucher.

\section{Glitches}

During the first few days of data collection, a particularly challenging issue emerged as a few of the email invites sent out by Myfood24 were being rejected by some of the participant's email providers, thus disabling those participants from recording data. Participants also reported that it was difficult to find some food items on Myfood24. A common problem reported with the GPS tracking devices was forgetting to change batteries daily or even forgetting to wear the devices! Collecting food purchase receipts proved to be relatively simple, however, on occasion some receipts lacked valuable information such as the name, address and postcode of the retail facility. Such omissions can compromise the quality of data.

Working closely and collaboratively with the cohort as they collected data enabled timely solutions to be found to some of the issues encountered by participants. However, whilst some of these issues were resolved within the life of the pilot study, many were not because the nature of the problem encountered was design-related rather than user-related, for example Myfood24 lacked an online self help feature or a forum to help users resolve issues themselves. The limited search function on Myfood24 is in need of adaptation to accommodate more UK food brands in its databases [22]. Similarly, improvements to the design of GPS tracking devices recommend manufacturers produce smaller GPS devices which can hold a charge for a longer time [23]. Other common problems encountered such as missing information on receipts was resolved more quickly and pragmatically by asking participants to check the receipts for such information before leaving food outlets and asking them to jot it down on the receipt themselves if this indeed was missing.

\section{The validity of methodological triangulation}

It is suggested in the methods literature that the use of triangulation to achieve completeness of data enables a more holistic, contextual portrayal and enriched understanding of a phenomena under investigation [24]. This form of triangulation is primarily concerned with collecting multiple perspectives, from different sources, about the phenomena being investigated to gain a complete picture of the issue which, in turn, contributes towards the comprehensiveness of a study [21]. This particular study deployed within method triangulation which trialled the integration of five quantitative methods. The researcher reasoned that a multiple methods approach such as this would offer a suitably wide enough lens with which to view some of the many complexities associated with the determinants of obesity [1]. The approach was also chosen for complementarity purposes $[21,25]$ as data derived from a single method would be insufficient to reflect the full extent of people's activity within food environments. The main purpose of a complementarity design is to explore different, yet complementary aspects of the same issue [26].

To illustrate this point, GPS data for example could only help us determine an individual's general activity space, whereas the receipts data provided by participants showing where they purchased food enabled us to identify specific food outlet locations. Since each of the five methods used in this study had different strengths and weaknesses, it was hoped 
that a research design that integrated them would provide complementarity, yield completeness, give rich insightful data and unveil irregularities [21]. According to Creswell \& Clark [27], timing is another essential factor to be considered when triangulating methods. The timing here refers to a temporal order when using the data to answer research questions and it can be either concurrent or sequential. This research used a concurrent approach whereby all data were collected, analysed and interpreted at roughly the same time. That means different methods were used simultaneously to collect data and the findings from each method were complementary [21]. This is contrary to a sequential design where one method and findings are used to inform the subsequent methods and phases of study [21].

The logistics of triangulating methods in research has been documented as a key challenge [25] and the experience of triangulating multiple methods in this study concurs with that general appraisal. More specifically, the researchers involved in this pilot study found triangulation to be resource and time intensive, both in terms of designing the research and its execution. The choice to trial new methods necessitated specialist GIS training before the GPS data could be analysed, and the general coordination activity involved-especially during data collection-added another unanticipated layer of complexity to the research process which ultimately lengthened the timeframe for data collection. Notwithstanding the above-mentioned challenges, there are several benefits to be derived from triangulating multiple methods in research as compared to using a single method approach. In this study, methodological triangulation provided the means to explore the multi-factorial complex issues of obesity by giving broader and different perspectives of the determinants of obesity and food environments [26].

Other benefits of methodological triangulation highlighted in the literature include the potential to yield more insightful and comprehensive data completeness and confirmation of findings and enhancing validity [28-31]. It is also suggested that triangulation of methods enables researchers to get the best of each method meanwhile overcoming each method's deficiencies [32]. Several researchers have also posited that triangulation could be helpful to overcoming the bias inherent in singlemethod research designs or mitigating the shortcomings of using a single research approach [33,34].

\section{Discussion}

Overall, the researchers consider the triangulation of multiple methods to have been successful in this pilot study as it provided them with a valuable way to collect insightful data on an individual's activity within food environments. Although it was not possible to perform statistical tests due to the small sample size used, interesting patterns did emerge from the data, specifically regarding the frequency with which certain of food outlets near the workplace were accessed - and those en route between home and the workplace. This supports Kwan's observation that an individual's activity of daily living (ADL) is complex and extends beyond the residential neighbourhood [35]. This reinforces the argument raised by other researches who contest the home neighbourhood as the unit of measurement for being too narrow [10]. It is expected that the full-scale study involving a larger sample size will shed more light on such emergent patterns.

From this study, it was observed that a high level of commitment was required from both participants and researchers and furthermore, that participants needed to have good levels of functional literacy for the successful collection of good quality data. This is corroborated by the fact that the burden of multiple data collection was eased by the wrap around support, encouragement and motivation offered to participants from the research team despite all the participants being highly educated, moderate-to-high socioeconomic status (SES) and employed with established routines. It is noteworthy that the lead researcher had to be available throughout the week of data collection to ensure participants were being compliant. Knowing all this, we now consider that to engage a much wider cohort of people at the lower end of SES gradient, with a lower level of education and the likelihood of greater stress, (i.e. typically those who are most likely to be obese or at risk of being obese), would be very challenging indeed. This implies that triangulating data in a similar fashion to this study might best be effective in a small-to-moderate scale study involving committed and wellsupported participants.

One way to address the challenges with triangulating methods in food environment research could be through the integration of dietary and geospatial data collection methods into a user-friendly tool like a smartphone app. Information and communication technology (ICT) has shown great potential of engaging a wide audience in a cost-effective and flexible way [36]. Mobile phones have been found to be an intuitively appealing platform given that they are portable, engaging and ubiquitous[37,38]. Studies have shown that apps like 'My Meal Mate' (MMM) and 'My Fitness pal' (MFP) are feasible and highly acceptable for use in weight management interventions compared to other approaches like web-based or paper-based methods [22,39-41].

The use of smartphone applications in food environment research is still underutilised. This is an area with a lot of potential and more exploration on the integration of dietary, physical activity and geospatial data collection methods needs to be considered. This would make data collection more innovative and accessible across a greater diversity of individuals and communities-including the growing number of smart-phone users in developing nations-countries whose populations are now beginning to reflect a trend toward obesity already established in the West.

\section{Conclusion}




\section{Juniper Online Journal of Public Health}

Methodological triangulation is feasible in food environment research and it can be useful if its benefits and challenges are well considered before the outset of research. Where appropriately deployed, methodological triangulation can provide a deeper and wider view of the issue under investigation despite the challenges that exist. With the complexity of food environments and obesity, triangulation offers promising prospects and avenues to advance research in these domains.

\section{References}

1. Butland B, Jebb S, Kopelman P, Mcpherson K, Thomas S, et al. (2007) Tackling obesities: future choices. Project report. Foresight. Tackling obesities: future choices. Foresight Project report.

2. Vandenbroeck I, Goossens J, Clemens M (2007) Foresight Tackling obesities: future choices-obesity systems atlas. Government Office for Science UK

3. Chaix B, Meline J, Duncan S, Jardinier L, Perchoux C (2013) Neighbourhood environments, mobility, and health: towards a new generation of studies in environmental health research. Rev Epidemiol Sante Publique 61(Suppl 3): 139-145.

4. Townshend T, Lake AA (2009) Obesogenic urban form: theory, policy and practice. Health Place 15(4): 909-916.

5. Burgoine T, Forouhi NG, Griffin SJ, Wareham NJ, Monsivais PJ (2014) Associations between exposure to takeaway food outlets, takeaway food consumption, and body weight in Cambridgeshire, UK: population-based, cross-sectional study. BMJ 2014: 348-1464.

6. Cobb LK, Appel LJ, Franco M, Jones-Smith JC, Nur A, et al. (2015) The relationship of the local food environment with obesity: a systematic review of methods, study quality, and results. Obesity 23 (7): 13311344 .

7. Gamba RJ, Schuchter J, Rutt C, Seto EY (2015) Measuring the food environment and its effects on obesity in the United States: a systematic review of methods and results. J Community Health 40(3): 464-475.

8. Caspi CE, Sorensen G, Subramanian S, Kawachi I (2012) The local food environment and diet: a systematic review. Health place 18 (5): 1172 1187.

9. Wilkins EL, Morris MA, Radley D, Griffiths CJ (2017) Using Geographic Information Systems to measure retail food environments: discussion of methodological considerations and a proposed reporting checklist (Geo-FERN). Health \& Place 44: 110-117.

10. Cummins S (2007) Commentary: Investigating neighbourhood effects on health-avoiding the Local Trap. Int J Epidemiol 36(2): 355-357.

11. Chaix B (2009) Geographic life environments and coronary heart disease: a literature review, theoretical contributions, methodological updates, and a research agenda. Annu Rev Public Health 30: 81-105.

12. Inagami S, Cohen DA, Finch BK (2007) Non-residential neighborhood exposures suppress neighborhood effects on self-rated health. Social Science \& Medicine 65 (8): 1779-1791.

13. Kwan MP, Weber J (2003) Individual accessibility revisited: implications for geographical analysis in the twenty-first century. Geographical Analysis 35(4): 341-353.

14. Matthews S (2008) The salience of neighborhood: some lessons from sociology. American Journal of Preventive Medicine 34 (3): 257-259.

15. Rainham D, Mcdowell I, Krewski D, Sawada M (2010) Conceptualizing the healthscape: contributions of time geography, location technologies and spatial ecology to place and health research. Social Science \& Medicine 70(5): 668-676

16. Saarloos D, Kim JE, Timmermans H (2009) The built environment and health: Introducing individual space-time behavior. 6 (6): 1724-1743.

17. Christian WJ (2012) Using geospatial technologies to explore activity-based retail food environments. Spatial and spatio-temporal epidemiology 3(4): 287-295.

18.Zenk SN, Schulz AJ, Matthews SA, Odoms-Young A, Wilbur J, et_al. (2011) Activity space environment and dietary and physical activity behaviours: a pilot study. Health Place 17(5): 1150-1161.

19. Kestens Y, Lebel A, Daniel M, Thériault M, Pampalon R (2010) Using experienced activity spaces to measure foodscape exposure. Health Place 16(6): 1094-1103.

20. Cetateanu A, Jones A (2016) How can GPS technology help us better understand exposure to the food environment? A systematic review. SSM-Population Health 2: 196-205.

21. Casey D, Murphy K (2009) Issues in using methodological triangulation in research. J Nurse researcher 16 (4): 40-55.

22. Carter MC, Burley V, Nykjaer C, Cade JE (2013) 'My Meal Mate'(MMM): validation of the diet measures captured on a smartphone application to facilitate weight loss. British Journal of Nutrition 109(3): 539-546.

23. Krenn PJ, Titze S, Oja P, Jones A, Ogilvie D (2011) Use of global positioning systems to study physical activity and the environment: a systematic review. American Journal of Preventive Medicine 41(5): 508-515.

24. Jick TD (1979) Mixing qualitative and quantitative methods: Triangulation in action. J Administrative science quarterly 24 (4): 602-611.

25. Tashakkori A, Teddlie C, Teddlie CB (1998) Mixed methodology: Combining qualitative and quantitative approaches. New Delhi, India.

26. Davis DF, Golicic SL, Boerstler CN (2011) Benefits and challenges of conducting multiple methods research in marketing. Journal of Academic Marketing 39 (3): 467-479.

27. Creswell JW, Clark VLP (2017) Designing and conducting mixed methods research. Sage publications London, UK.

28. Halcomb EJ, Andrew S (2005) Triangulation as a method for contemporary nursing research. Journal of Nurse Researcher 13(2): 71-82.

29. Redfern S, Norman I (1994) Validity through triangulation. Nurse Researcher 2(2): 41-56.

30. Bradley S (1995) Methodological triangulation in healthcare research. J Nurse Researcher 3(2): 81-89.

31. Silverman D (2001) Interpreting qualitative data.

32. Denzin NK (2017) The research act: A theoretical introduction to sociological methods New York: Routledge, USA

33. Boyd CO (2001) Combining qualitative and quantitative approaches.

34. Thurmond VA (2001) The point of triangulation. Journal of Nursing Scholarship 33(3): 253-258.

35. Kwan MP (2004) GIS methods in time-geographic research: Geocomputation and geovisualization of human activity patterns. Geografiska Annaler: Series B Human Geography 86(4): 267-280.

36. Carter MC, Albar SA, Morris MA, Mulla UZ, Hancock, N, (2015) Development of a UK online 24-h dietary assessment tool: myfood 24 . Nutrients 7 (6): 4016-4032.

37. Boulos MNK, Wheeler S, Tavares C, Jones RJ (2011) How smartphones are changing the face of mobile and participatory healthcare: an overview, with example from eCAALYX. Bio Medical Engineering OnLine 10(1): $10-24$

38. Klasnja P, Pratt W (2014) Managing health with mobile technology. J interactions 21(1): 66-69.

39. Laing BY, Mangione CM, Tseng CH, Leng M, Vaisberg E, (2014) Effec- 
tiveness of a smartphone application for weight loss compared with usual care in overweight primary care patients: a randomized, controlled trial. Annals of internal medicine 161(10): 5-12.

40. Cummins S, Macintyre S (2006) Food environments and obesity-neighbourhood or nation? Int J Epidemiology 35(1): 100-104.

This work is licensed under Creative Commons Attribution 4.0 License

DOI: 10.19080/JOJPH.2018.04.555636
41. Tomlinson M, Solomon W, Singh Y, Doherty T, Chopra M, et_al. (2009) The use of mobile phones as a data collection tool: a report from a household survey in South Africa. BMC Medical Informatics Decision Making 9(1): 9-51.

\section{Your next submission with Juniper Publishers will reach you the below assets}

- Quality Editorial service

- Swift Peer Review

- Reprints availability

- E-prints Service

- Manuscript Podcast for convenient understanding

- Global attainment for your research

- Manuscript accessibility in different formats

( Pdf, E-pub, Full Text, Audio)

- Unceasing customer service

Track the below URL for one-step submission https://juniperpublishers.com/online-submission.php 